\title{
退耕还林和地理特征对土壤侵蚀的关联影响
} 以陕西省 107 个县区为例

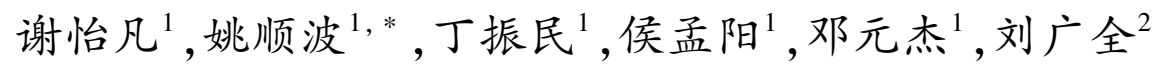 \\ 1 西北农林科技大学经济管理学院,杨凌 712100 \\ 2 中国水利水电科学研究院, 北京 100038
}

摘要:在自然要素和社会经济要素交互作用下,科学评估退耕还林工程对土壤侵蚀的影响,对生态修复政策的可持续性具有重 要意义。在利用 RUSLE 模型评估陕西省土壤侵蚀强度时空演变特征的基础上,构建纳人社会经济因素的退耕还林防治土壤侵 蚀效应研究框架,基于面板数据固定效应模型,探究地理特征对退耕还林工程防治土壤侵蚀的影响。结果表明: (1)2000一2015 年陕西省土壤侵蚀强度显著降低, 全省土壤侵蚀总量由 2000 年 34166.42 万 $\mathrm{t}$, 下降至 2015 年 28260.69 万 $\mathrm{t}$, 区域土壤侵蚀强度 及其时空变化特征存在显著异质性, 陕北地区土壤侵蚀水平最高, 同时下降也最为显著。(2退耕还林工程对防治土壤侵蚀有显 著的正向影响,表现为投资金额每增加 1 万元,土壤侵蚀总量下降 $26.30 \mathrm{t}$, 且资金投人的生态效益存在显著滞后效应。(3)地理 特征在退耕还林工程防治土壤侵蚀效应中存在显著调节作用, 相较关中和陕南地区, 陕北地区退耕还林工程防治土壤侵蚀效应 更为显著。坡度和降雨对工程的防治土壤侵蚀效应存在显著负向调节作用,而日照时间则表现出正向调节作用。决策者应充 分考虑自然地理因素和社会经济因素对生态系统服务的复合作用机理以实现生态修复政策的可持续性。

关键词:退耕还林; 土壤侵蚀;地理特征;调节作用;面板数据固定效应模型

\section{The Grain for Green project, geographical features and soil erosion: Taking 107 counties in Shaanxi Province as examples}

\author{
XIE Yifan ${ }^{1}$, YAO Shunbo ${ }^{1, *}$, DING Zhenmin ${ }^{1}$, HOU Mengyang ${ }^{1}$, DENG Yuanjie ${ }^{1}$, LIU Guangquan ${ }^{2}$ \\ 1 College of Economic Management, Northwest A\&F University, Yangling 712100, China \\ 2 China Institute of Water Resources and Hydropower Research, Beijing 100038, China
}

\begin{abstract}
In order to respond to the seriously ecological problems caused by soil erosion since the last century, Shaanxi Province has been implementing the Grain for Green project since 1999 as a pilot province. The project has achieved remarkablely ecological benefits in the past 20 years, and the regional soil erosion has also been under effective control. While soil erosion, as one of the important indicators of ecosystem services, is the result of the interaction between natural factors and human factors, so it's significant to assess the impact of the Grain for Green project on soil erosion under the interaction of natural factors and socio-economic factors for the sustainability of ecological restoration policies. Based on the analysis of the spatial and temporal evolution of soil erosion levels in 107 counties of Shaanxi Province using the RUSLE model, this study explored the impacts of geographic characteristics on the prevention and control of soil erosion by the Grain for Green project using the fixed-effect model of panel data. The results showed that: (1) from 2000 to 2015 , the level of soil erosion in Shaanxi Province decreased significantly and the total amount of soil erosion decreased from 341.66× $10^{6} \mathrm{t}$ in 2000 to $282.61 \times 10^{6} \mathrm{t}$ in 2015 . Besides, there was obvious heterogeneity in regional soil erosion intensity and its spatio-temporal variation characteristics. For example, the soil erosion intensity in Northern Shaanxi region was the highest
\end{abstract}

基金项目:林业公益性行业科研专项经费项目(201504424);国家自然科学基金项目(71773091)

收稿日期: 2021-01-06; 采用日期:2021-03-27

*通讯作者 Corresponding author.E-mail: yaoshunbo@163.com 
meanwhile the decline was also the most precipitous, while Guanzhong region and Southern Shaanxi region were not. (2) The Grain for Green project had a significantly positive impact on the prevention and control of soil erosion. It showed that for every 10,000 yuan increased in investment, the amount of soil erosion decreased by 26.30 t. At the same time, compared with Guanzhong region and Southern Shaanxi region, the effect of soil erosion control in Northern Shaanxi was more significant. (3) The geographical characteristics had a significant moderating effect on the effect of the Grain for Green project on soil erosion control. Slope and rainfall had a significant regulating effect on the soil erosion control effect of the project, while the sunshine duration showed a positive regulating effect. Policy makers should fully consider the combined mechanism of natural geographic factors and socio-economic factors on ecosystem services to achieve the sustainability of ecological restoration policies.

Key Words: the Grain for Green project; soil erosion; geographical features; moderating effect; panel fixed effects model

土壤侵蚀是导致土地退化和生态系统服务功能受损的全球性问题 ${ }^{[1]}$, 仅 2001-2012 年全球由于土地利 用变化导致的土壤侵蚀总量增加 $2.5 \%$ 。同样,中国的土壤侵蚀问题也不容忽视,全国风蚀和水蚀面积占国 土面积的 $37 \%{ }^{[3]}$,尤其是西部黄土高原地区, 上世纪以来水土流失导致的生态问题十分严峻, 区域社会经济 发展被严重制约 ${ }^{[4-5]}$ 。因此, 为应对土壤侵蚀问题,各个国家和地区采取多种措施 ${ }^{[6]}$,其中以退耕还林工程为 代表的生态修复工程是中国 20 世纪 90 年代专门应对土壤侵蚀提出的生态修复方案。工程实施 20 年来取得 显著生态成效 ${ }^{[7-8]}$, 其中区域土壤侵蚀状况也得到一定程度改善, 而土壤侵蚀作为衡量生态系统服务功能的 重要指标, 是自然因素和人为因素交互作用的结果 ${ }^{[9]}$, 受到大量学者的关注和研究。科学评估在自然要素和 社会经济要素交互作用下退耕还林工程对土壤侵蚀的影响,对于区域生态系统可持续发展和生态文明建设有 重要意义。

基于以上研究背景, 学术界关于退耕还林工程对土壤侵蚀的影响研究主要围绕利用土壤侵蚀模型定量评 估退耕前后土壤侵蚀的时空变化特征 ${ }^{[10-12]}$, 不同地形地貌下土壤侵蚀对生态修复政策和自然地理要素的响

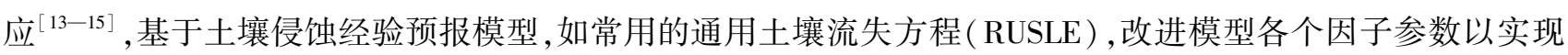
参数本地化 ${ }^{[16]}$, 以及对土壤侵蚀驱动因素的探究 ${ }^{[17-18]}$ 等方面进行。李天宏 ${ }^{[10]}$ 等利用 RUSLE 模型定量评估 黄土高原典型地区延河流域 2000一-2010 年土壤侵蚀状况, 结果表明流域土壤侵蚀模数在生态建设的作用下 显著降低。王欢 ${ }^{[13]}$ 等基于地理探测器探讨喀斯特地区不同地形地貌下土壤侵蚀的影响因素, 结果表明土地 利用对土壤侵蚀的影响最为显著，且区域土壤侵蚀的影响机制随着地形地貌的不同存在显著的空间异质性。 刘文超 ${ }^{[16]}$ 等利用高精度梯田数据实现对陕北地区水土保持措施因子的改进, 并评估了区域退耕还林前后土 壤侵蚀时空演变特征, 指出耕地转为林地和草地对于改善土壤侵蚀效果最为显著。此外 Kong ${ }^{[6]}$ 等借助结构 方程模型探究长江流域中上游退耕还林工程, 城镇化, 农业发展, 人口增长以及土壤侵蚀之间的关系, 并指出 退耕还林工程通过将耕地转为林地和草地直接增强土壤保持效应的同时,还通过促进城镇化间接减弱区域土 壤侵蚀强度。上述工作为土壤侵蚀的定量评估提供了有价值的样本研究, 但仍存在需要完善和进一步挖掘的 地方: (1) 在生态系统与社会经济因素交互作用下,探究县域尺度退耕还林工程对土壤侵蚀的影响研究相对 较少, 而将社会经济因素纳人研究框架更有利于科学评估生态修复政策, 促进生态政策的可持续性 ${ }^{[19]}$; (2) 地 理特征因素对土壤侵蚀的影响研究多建立在土壤侵蚀的时空变化特征上,缺乏进一步与政策因素交互作用的 机理分析; (3) 在探究退耕还林工程对土壤侵蚀的影响时, 多直接通过土地利用变化中耕地转为林地和草地, 或只使用单一的哑元变量来表征政策影响,容易造成对效果评价的偏差。

20 世纪严重的土壤侵蚀问题, 使得陕西省最早于 1999 年作为试点省份实施退耕还林工程, 其工程实施 范围广, 投资大,持续时间长, 同时区域社会经济发展和自然地理特征均存在显著的空间异质性,为在社会经 济因素和自然地理因素交互作用下研究退耕还林工程对土壤侵蚀的影响提供了理想样本。本研究首先通过 修正通用土壤流失方程 (RUSLE) 对陕西省 2000-2015 年的土壤侵蚀进行定量评估,在获得县域水平上土壤 侵蚀数据后, 结合退耕还林投资金额数据, 将社会经济因素纳人计量实证, 并利用面板数据固定效应模型, 在 
社会经济因素和自然因素交互作用下,探究不同地理区位特征以及自然地理条件如降雨,坡度, 日照时间等对 退耕还林工程防治土壤侵蚀效应的调节作用, 丰富现行生态修复政策的生态效果评价体系, 同时也为区域制 定可持续的生态修复政策提供科学依据。

\section{1 研究区概况与研究方法}

\section{1 研究区概况}

陕西省地处中国西北内陆, 地理位置介于东经 $105^{\circ} 29^{\prime}-111^{\circ} 15^{\prime}$, 北纬 $31^{\circ} 42^{\prime}-39^{\circ} 35^{\prime}$, 占地面积达 20.58 万 $\mathrm{km}^{2}$, 海拔在 $800-3000 \mathrm{~m}$, 年均降雨在 300- $1300 \mathrm{~mm}$, 年均气温在 7- $16^{\circ}$ 。中国南北方分界线秦岭淮 河线横穿陕西省腹地, 以秦岭为界南北分别位于长江、黄河两大流域, 境内气候差异显著, 地形地貌变化多样, 由陕北、关中和陕南三大地区组成: 陕北位于黄土高原地区, 地形沟壑纵横, 是典型的黄土高原丘陵沟壑区, 雨 量较少, 煤、石油等能源丰富, 植被类型以温带灌丛草原和温带落叶阔叶林为主, 如长芒草, 辽东栋等; 关中位 于秦巴山区和黄土高原之间, 地势平坦, 雨量适中, 是主要的粮食产区, 和人口聚集地区, 植被类型以人工植 被, 温暖性渭河盆地落叶果树为主, 如苹果, 狝猴桃等; 陕南地区地处秦巴山区, 地形以山地丘陵为主, 雨量充 足,水和林木资源丰富,植被类型以温带和亚热带落叶阔叶林和亚热带灌丛为主,如栓皮栋, 锐齿栋等。

由于陕西省独特的气候和地形地貌特征, 加上粮食生产, 能源开发等各种高强度人类活动对生态系统的 巨大压力, 长期以来区域水土流失问题十分严峻, 同时陕西省作为退耕还林工程的试点省份, 自 1999 年开展 退耕还林工程以来累计总投资超过 400 亿元, 森林覆盖率由工程实施前的 $30.92 \%$ 增长到 $43.06 \%$, 黄土高原 区输沙量从 2000 年的 8 亿 $\mathrm{t}$ 减少到近 4 亿 $\mathrm{t}^{[20]}$, 生态效果显著。截止 2015 年, 陕西省社会经济发展变化显 著, 人均国内生产总值从 2000 年的 4900 元增长到 2015 年的 47500 元, 粮食产量由 2000 年的 1089 万 $\mathrm{t}$ 增长 到 2015 年的 1204 万 $\mathrm{t}$ 。

\section{2 机制分析与计量模型构建}

\subsection{1 机制分析}

退耕还林工程通过给予退耕农户粮食补贴以及现金补贴, 实现坡耕地退耕成林地和草地的土地覆盖变 化 ${ }^{[21]}$, 即通过改变土地覆盖/利用方式来对土壤侵蚀产生影响, 减缓和防治水土流失。而土地利用方式的改 变和社会经济发展密不可分, 比如人口的转移 (生态移民, 劳动力转移)、城镇化的加快 ${ }^{[6]}$ 、产业结构的改变等 都同土地利用变化紧密联系。因此将社会经济因素纳人到退耕还林工程对土壤侵蚀的影响机制当中, 对生态 修复政策的可持续性有重要作用。

地理特征对退耕还林工程土壤侵蚀防治效应的影响主要表现在两方面,一是由于地理区位不同,退耕还 林工程的生态效益也会因区域自然条件和社会经济发展的差异而表现出空间异质性,进而工程投人资金的有 效性也会随区域改变, 即不同地理区位退耕还林的植被生长效果呈现差异, 从而影响植被覆盖对地表土壤的 保护效应,使土壤侵蚀的变化也具有空间异质性。二是自然地理条件如坡度,降雨和日照时间等对土壤侵蚀 的发生和作用机理影响显著, 同时具体到县域尺度上,不同县区坡度,降雨和日照时间等自然地理条件的空间 差异较大。具体表现为坡度越大, 则区域土壤受到降雨侵蚀的影响就越明显, 对于整个区域而言水土流失就 更容易。区域降雨量越大, 降雨对土壤表层冲击也越强, 对区域整体而言土壤侵蚀的风险也会升高, 同时降雨 因素对植物生长也有显著影响, 即降雨对退耕还林工程防治土壤侵蚀效应有显著的调节作用。日照时间的不 同也会通过影响植被生长状况, 进而对区域土壤侵蚀产生影响。总体而言, 在退耕还林工程通过改变地表覆 盖对区域土壤侵蚀产生作用的同时, 地理特征会在其中产生调节效应。那么这种调节效应在县区尺度上是否 显著, 以及不同地理特征具体起到怎样的调节作用,都需要进一步构建计量模型进行验证。

\subsection{2 研究框架}

通过上述机制分析, 进一步确定本研究的框架, 如图 1 所示。研究主要聚焦于退耕还林, 地理特征和土壤 侵蚀三者的关系, 即退耕还林工程通过改变土地利用结构, 增加地表植被覆盖对区域土壤侵蚀产生影响 ${ }^{[5]}$, 
而土壤侵蚀作为土地利用变化引起的主要环境效应之 一, 是自然和人为因素交互作用的结果 ${ }^{[9]}$,一方面受到 区域地理特征如降雨、坡度等的影响, 另一方面区域的 土地利用变化和格局也会受到地理特征的影响,进而对 退耕还林工程的生态效果产生作用。因此本研究以退 耕还林,地理特征和土壤侵蚀三者的关系为研究出发 点,建立纳人社会经济因素的研究框架。同时本研究根 据陕西省区域自然地理条件的差异将地理特征分为地 理区位特征即陕北,陕南和关中三大地区,以及降雨、坡 度和日照时间等自然地理特征, 来探究其在退耕还林工 程防治土壤侵蚀效应的调节作用。

\subsection{3 模型构建}

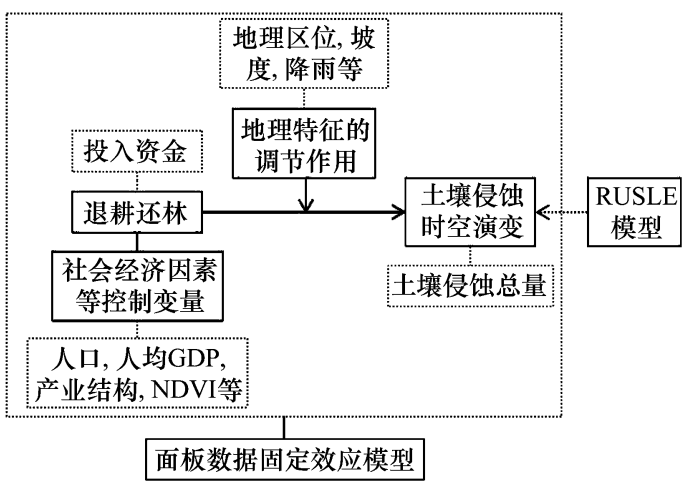

图 1 研究框架

基于以上理论机制分析, 同时考虑到最小二乘法

(OLS) 容易因遗漏变量而带来内生性问题,本研究使用面板数据则在一定程度上可解决此问题。此外本研究 经过豪斯曼检验, 检验结果拒绝原假设,认为应该使用固定效应模型 ${ }^{[22]}$ 。因此本研究选择面板数据固定效应 模型进行计量实证 ${ }^{[23]}$, 本文实证部分基础回归模型设置如下:

$$
Y_{i t}=\lambda \mathrm{INV}_{i t}+X_{i t}{ }^{\prime} \varphi+\alpha_{i}+\beta_{t}+\mu_{i t}
$$

其中, $i$ 和 $t$ 分别表示县区和年份, $Y_{i t}$ 表示土壤侵蚀水平, $\mathrm{INV}_{i t}$ 表示退耕还林投人资金, $\lambda$ 表示解释变量退 耕还林投人资金系数, $X_{i t}{ }^{\prime}$ 表示控制变量矩阵, $\varphi$ 表示控制变量的系数向量, $\alpha{ }_{i}$ 和 $\beta_{t}$ 分别表示县区固定效应和 时间固定效应, 分别用来解决不随时间改变但随个体变化的遗漏变量问题,和不随个体改变但随时间变化的 遗漏变量问题 ${ }^{[22]}, \mu_{i t}$ 表示随机扰动项。

本研究通过加人地理特征变量与投资金额的交叉项来探究地理区位以及自然地理条件对退耕还林工程 防治土壤侵蚀效应的调节作用,其回归模型设置如下：

$$
Y_{i t}=\delta \mathrm{GEO}_{i} \times \mathrm{INV}_{i t}+\lambda \mathrm{INV}_{i t}+X_{i t}{ }^{\prime} \varphi+\alpha_{i}+\beta_{t}+\mu_{i t}
$$

其中, $\mathrm{GEO}_{i}$ 表示各县区地理区位特征和自然地理条件的前定变量, 它在样本期内基本不随时间改变或变 动幅度较小, $\delta$ 表示交叉项的系数。

\subsection{4 变量说明}

(1) 被解释变量。本文将依据 RUSLE 模型求得的土壤侵蚀模数 (Soil erosion, 缩写为 $S E$ ), 单位为 $\mathrm{t} / \mathrm{hm}^{2}$, 以及地区土壤侵蚀总量 (Total soil erosion, 缩写为 TSE), 单位为万 $\mathrm{t}$, 作为被解释变量。土壤侵蚀模数 (SE) 是 利用 ArcGIS 平台的区域统计功能求得区域平均土壤侵蚀模数, 反应区域的平均土壤侵蚀程度, 土壤侵蚀模数 表示单位面积和时间内土壤侵蚀的重量;土壤侵蚀总量表示地区发生土壤侵蚀的总重量。使用土壤侵蚀模数 (SE) 作为被解释变量来增强模型的稳健性。

(2) 解释变量。本文使用退耕还林工程的投入资金 (Investment, 缩写为 INV), 单位为万元, 作为核心解释 变量,由县区历年退耕认定面积和粮食补贴标准计算而得。

(3) 控制变量。根据以往研究 ${ }^{[6]}$ 中社会经济因素对土壤侵蚀的影响的变量选取,以及土壤侵蚀,退耕还 林工程与社会经济发展之间互相作用的相关理论基础, 确保计量结果具有可靠性和独立性,本研究选择以下 变量作为控制变量。城镇化率 (Urbanization rate, 缩写为 URBR) 为建设用地面积占比; 产业结构 (Industrial structure, 缩写为 $I S$ ) 用县区第二产业生产总值占比表示; 人均国内生产总值 (Per GDP, 缩写为 PGDP), 单位 为万元; 人口密度 (Population density, 缩写为 $P D$ ), 单位为人 $/ \mathrm{km}^{2}$; 农村人均年收人 (Per rural income, 缩写为 PRI), 单位为万元; 粮食产量 (CROP), 单位为 $\mathrm{t}$ 。此外植被归一化指数 (NDVI) 在较大时空尺度上反映植物生 长状态和覆盖范围, 可表征区域自然资源禀赋特征, 将其纳人控制变量, 提高计量模型参数估计的无偏性。 
(4)地理特征变量。本文使用的自然条件变量有坡度 (SLOP), 单位为度,年降雨 (Annual precipitation, 缩 写为 PRE), 单位为 $\mathrm{mm}$, 和日照时间 (Sunshine duration, 缩写为 SUN), 单位为 $\mathrm{h} 。$ 此外将陕北 (SHANBEI), 关 中 (GUANZHONG) , 陕南(SHANNAN) 作为虚拟变量, 表征地理区位的调节变量。

\section{3 修正通用土壤侵蚀模型 RUSLE}

本研究选用修正通用土壤流失方程 RUSLE 模型进行土壤侵蚀的定量评估 ${ }^{[11]}$,表达式如下:

$$
A=R \times K \times L \times S \times C \times P
$$

式中, $A$ 为土壤侵蚀模数, 单位是 $\mathrm{t} \mathrm{hm}^{-2} \mathrm{a}^{-1} ; R$ 为降雨侵蚀力因子, 单位为 $\mathrm{MJ} \mathrm{mm} \mathrm{hm} \mathrm{h} \mathrm{h}^{-1} \mathrm{a}^{-1} ; K$ 为土壤可蚀性 因子,单位为 $\mathrm{t} \mathrm{hm}^{2} \mathrm{~h} \mathrm{hm}^{-2} \mathrm{MJ}^{-1} \mathrm{~mm}^{-1} ; L$ 为坡长因子; $S$ 为坡度因子; $C$ 为植被覆盖与管理因子; $P$ 为水土保持 措施因子。

\subsection{1 降雨侵蚀力因子 $R$}

降雨侵蚀力因子反映降雨引起土壤分离和搬运的动力大小, 根据对类似研究中不同算法的比较和数据获 取情况,本研究选择章文波等 ${ }^{[24]}$ 提出的年平均雨量简易算法模型来估算侵蚀力, 计算公式如下:

$$
R=\alpha 1 P^{\beta 1}
$$

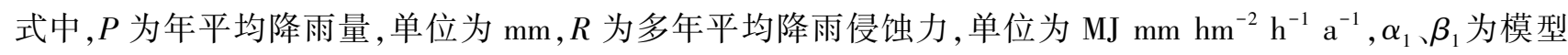
参数。

\subsection{2 土壤可蚀性因子 $K$}

土壤可蚀性是表征土壤性质对降雨侵蚀敏感程度的指标, 反映土壤内在的理化性质,如砂砾百分比,有机 碳百分比的大小对降雨侵蚀的影响程度。RUSLE 模型中将土壤可蚀性定义为标准小区内单位降雨侵蚀力引 起的土壤流失率 ${ }^{[25]}$ 。本研究使用的数据来源于国家地球系统科学数据中心提供的陕西省土壤可蚀性因子 $K$ 值图,空间分辨率为 $30 \mathrm{~m}$ 。

\subsection{3 坡度坡长因子 $L S$}

众多坡面或流域尺度的土壤侵蚀研究表明,地形因素是诱发土壤侵蚀的直接因子,坡度坡长因子 $L S$ 反映 了地形的坡度坡长对土壤侵蚀的影响,其数值在 0-1 之间。本研究 $L S$ 的计算基于陕西省 DEM 数据,利用符 素华等 ${ }^{[26]}$ 提出的修正后的土壤侵蚀模型地形因子计算工具生成研究区的坡度坡长因子图层, 以及坡度图层。

\subsection{4 植被覆盖与管理因子 $C$}

在 RUSLE 模型中 $C$ 因子反映植被覆盖和管理措施对土壤侵蚀的影响,被认为是影响土壤侵蚀最敏感的 因子,介于 $0-1$ 。本文根据相关研究 ${ }^{[5,13]}$, 采用蔡崇法等 ${ }^{[25]}$ 提出的基于植被覆盖度 $c$ 的计算公式,对林地、草 地和未利用地 $C$ 因子进行计算, 旱地和水田的 $C$ 因子分别赋值 ${ }^{[27]}$ 为 0.44 和 0.1 , 水域和建设用地赋值为 0 。

$$
C=\left\{\begin{array}{cl}
1 & 0 \leqslant c \%<0.096 \\
0.6508-0.3436 \lg (c \%) & 0.096 \leqslant c \%<78.3 \\
0 & c \%>78.3
\end{array}\right.
$$

\subsection{5 水土保持措施因子 $P$}

水土保持措施因子一般根据地类进行赋值, $P$ 值范围在 0 到 1 之间, 0 表示不发生土壤侵蚀的地区, 1 表 示未采取任何水保措施的地区。根据相关研究 ${ }^{[10]}$ 将建设用地和水域赋值为 0 , 未利用地、林地和草地一般未 采取水土保持措施赋值为 1 , 耕地根据坡度的不同赋予不同的 $P$ 值, 见下表。

\section{4 数据来源}

土壤侵蚀数据根据修正通用土壤侵蚀方程 (RUSLE) 计算而得; 退耕还林投资数据来源于中南林业调查 规划设计院; 四期土地利用覆被数据来源于中国科学院资源环境数据中心 ( http://www.resdc.cn), 其空间分 辨率为 $30 \mathrm{~m}^{[28]}$; 归一化植被指数 (NDVI) 数据、高程 (DEM) 数据来源于地理空间数据云 (https://www.gscloud. $\mathrm{cn} / \mathrm{search}$ ); 陕西省矢量数据来源于国家基础地理信息中心 ( http ://www.webmap.cn) ; 日照时间、降雨等气象 数据来源于中国气象局网站 (http://data.cma.cn/) ; 土壤数据来源于国家地球系统科学数据中心 ( http:// 
www.geodata.cn); 其他统计数据如人均 GDP, 人口,粮食产量等均来源于《陕西省统计年鉴》 ${ }^{[29]}$ 。本研究使用 的空间数据分辨率统一为 $30 \mathrm{~m}$,空间坐标系均为 Krasovsky_1940_Albers。

表 1 不同坡度范围下耕地的 $\boldsymbol{P}$ 值 ${ }^{[27]}$

Table 1 The $P$ value of cultivated land in different slope range

\begin{tabular}{ccccccc}
\hline 坡度范围 Slope range & $0^{\circ}-5^{\circ}$ & $5^{\circ}-10^{\circ}$ & $10^{\circ}-15^{\circ}$ & $15^{\circ}-20^{\circ}$ & $20^{\circ}-25^{\circ}$ & $>25^{\circ}$ \\
\hline$P$ & 0.100 & 0.221 & 0.305 & 0.575 & 0.705 & 0.800 \\
\hline
\end{tabular}

\section{2 结果分析}

\section{$2.12000-2015$ 年陕西省土壤侵蚀时空特征}

2.1.1 壤侵蚀的时间变化

根据 RUSLE 模型计算结果得到陕西省及各地区 2000-2015 年土壤侵蚀状况 (表 2),2000 年到 2015 年 陕西省土壤侵蚀总量总体呈下降趋势,同时陕北、关中和陕南地区土壤侵蚀变化差异显著。

将研究区土壤侵蚀数据同其他相似地区做对比验证, 刘文超 ${ }^{[16]}$ 等利用高精度梯田数据评估陕北地区土 壤侵蚀时空特征的结果表明,陕北地区 2000 年,2010 年土壤侵蚀总量分别为 27488.07 万 t 和 15977.69 万 t, 本研究中提取陕北地区 2000 年和 2010 年土壤侵蚀总量分别为 18522.04 万 $\mathrm{t}$ 和 12486.99 万 $\mathrm{t}$, 数据的综合解 释力达到 $70 \%$ 以上,因此本研究数据结果的精度与误差也满足科研要求,可进行下一步分析。

从全省来看, 2000 年土壤侵蚀总量为 34166.42 万 $\mathrm{t}$, 其中陕北地区占比最大达到 $54.21 \%$, 超过关中和陕 南占比之和, 陕南地区次之, 关中地区最小; 到 2005 年减少至 31344.12 万 $\mathrm{t}$,下降明显; 到 2010 年再次减少近 $10 \%$,土壤侵蚀得到相对有效控制,但到 2015 年土壤侵蚀总量相较 2010 有所回升。从分区来看,陕北地区土壤 侵蚀总量在 2000-2015 年期间由 18522.04 万 $\mathrm{t}$ 下降至 13375.50 万 $\mathrm{t}$,下降近 30 个百分点, 而陕南和关中地区变 化总量则相对较小, 分别由 2000 年的 6236.78 万 $\mathrm{t}$ 和 9407.60 万 $\mathrm{t}$, 下降至 2015 年的 5665.43 万 $\mathrm{t}$ 和 9219.75 万 $\mathrm{t}$ 。

表 $22000-2015$ 年陕西土壤侵蚀量统计表/(万 $\mathrm{t}$ )

Table 2 Soil erosion in Shaanxi Province, 2000-2015

\begin{tabular}{|c|c|c|c|c|c|c|c|c|}
\hline & \multicolumn{2}{|c|}{2000 年 } & \multicolumn{2}{|c|}{2005 年 } & \multicolumn{2}{|c|}{2010 年 } & \multicolumn{2}{|c|}{2015 年 } \\
\hline & $\begin{array}{c}\text { 土壤侵蚀量 } \\
\text { Soil erosion/ } \\
\text { 万t }\end{array}$ & $\begin{array}{c}\text { 比例 } \\
\text { Percentage } / \%\end{array}$ & $\begin{array}{c}\text { 土壤侵蚀量 } \\
\text { Soil erosion/ } \\
\text { 万t }\end{array}$ & $\begin{array}{c}\text { 比例 } \\
\text { Percentage } / \%\end{array}$ & $\begin{array}{c}\text { 土壤侵蚀量 } \\
\text { Soil erosion/ } \\
\text { 万 } \mathrm{t}\end{array}$ & $\begin{array}{c}\text { 比例 } \\
\text { Percentage } / \%\end{array}$ & $\begin{array}{c}\text { 土壤侵蚀量 } \\
\text { Soil erosion/ } \\
\text { 万 } \mathrm{t}\end{array}$ & $\begin{array}{c}\text { 比例 } \\
\text { Percentage/\% }\end{array}$ \\
\hline 关中 & 6236.78 & 18.25 & 6181.87 & 19.72 & 5701.92 & 20.77 & 5665.43 & 20.05 \\
\hline 陕北 & 18522.04 & 54.21 & 15702.74 & 50.10 & 12486.99 & 45.49 & 13375.50 & 47.33 \\
\hline 陕南 & 9407.60 & 27.53 & 9459.51 & 30.18 & 9259.32 & 33.73 & 9219.75 & 32.62 \\
\hline 全省 & 34166.42 & 100.00 & 31344.12 & 100.00 & 27448.22 & 100.00 & 28260.69 & 100.00 \\
\hline
\end{tabular}

\subsection{2 土壤侵蚀的空间变化}

2000 年到 2015 年,陕西省土壤侵蚀模数空间分布及其变化特征的空间异质性较为显著。根据我国土壤 侵蚀分类分级标准 ${ }^{[30]}$, 将土壤侵蚀强度划分为 6 个级别, 如图 2 所示, 2000 年陕西省微度侵蚀主要集中分布 在关中地区的关中平原, 陕南地区的秦岭以及汉中平原地区, 陕北地区南部黄陵、黄龙县以及北部地区土壤侵 蚀强度较低。中度侵蚀、强度侵蚀和剧烈侵蚀主要集中在陕北地区的黄土丘陵沟壑区, 如延安市的安塞县、志 丹县、子长县、吴起县以及榆林市的子洲县、绥德县、米脂县等。关中地区北部山区, 以及陕南地区中部和南部 土壤侵蚀也以中、强度侵蚀为主。

如图 2 所示, 到 2015 年区域土壤侵蚀强度空间变化明显,2000 年上述中、强度侵蚀分布的地区, 土壤侵 蚀强度显著降低, 尤其是陕北地区最为明显。结合图 3 可知, 特别是退耕还林工程实施最具代表性的延安市, 其中安塞县、志丹县、吴起县、子长县等土壤侵蚀模数降低基本在 $5 \mathrm{t} / \mathrm{hm}^{2}$ 以上, 部分地区土壤侵蚀模数降低甚 
至超过 $10 \mathrm{t} / \mathrm{hm}^{2}$, 水土流失得到有效控制, 这也与类似研究的结论 ${ }^{[10,16]}$ 吻合, 进一步证明本研究模型模拟的可 靠性。同时关中地区北部长武县、旬邑县、印台区、陇县等土壤侵蚀模数也显著降低,陕南地区土壤侵蚀降低 主要零散分布在宁强县、勉县、石泉县等部分地区。

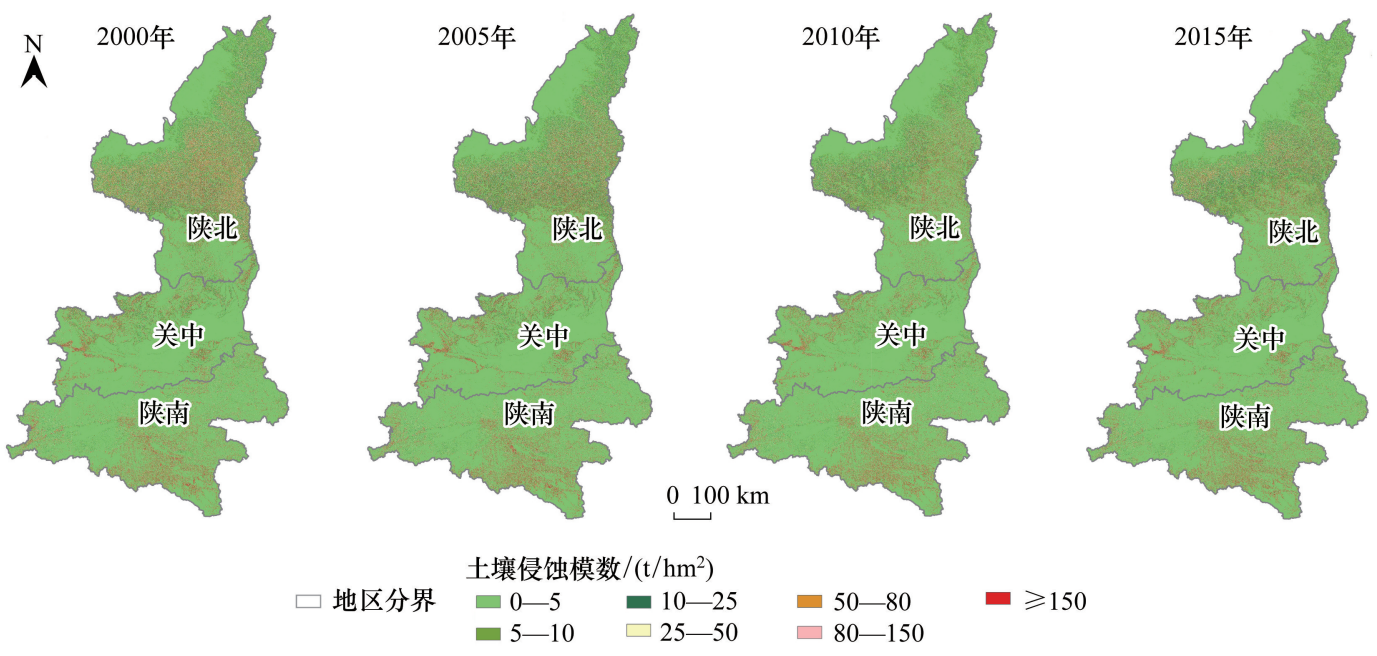

图 $22000-2015$ 年陕西省土壤侵蚀模数空间分布

Fig.2 Spatial distribution of soil erosion modulus of Shaanxi Province during 2000-2015

\section{2 计量实证检验结果}

\subsection{1 基础回归结果分析}

如表 3 所示,第一列 (1) 和 (2) 的基础回归分别表 示不考虑控制变量和考虑控制变量的模型,退耕还林工 程对土壤侵蚀均有显著的负向影响, 即退耕还林的投资 金额增加, 则土壤侵蚀总量就减少, 即工程的实施能显 著减少土壤侵蚀总量。控制其他条件不变,由表 3 中投 资金额 (INV) 对应的回归系数可知,退耕还林投资金额 每增加 1 万元则土壤侵蚀总量下降 26.30t。2000 年到 2015 年陕西省退耕还林累计投资金额从 7.77 亿元增加 到 303.28 亿元, 若控制其他条件不变, 则陕西省退耕还 林工程使得土壤侵蚀总量下降 7771.91 万 $\mathrm{t}$ 。对于被誉 为“退耕还林第一县” 的延安市吴起县, 2000-2015 年 累计投资金额增加 16.73 亿元, 相当于 2000-2015 年 退耕还林工程使土壤侵蚀总量下降 440.00 万 $\mathrm{t}$, 相比 2000 年的 1416.40 万 $\mathrm{t}$, 减少近 $30 \%$ 。

同时考虑到生态修复工程所带来的生态效益具有 $3-5 \mathrm{a}$ 的滞后期 ${ }^{[31-32]}$, 将解释变量投资金额滞后 3 期 $\left(\mathrm{INV}_{-3}\right)$ 带人计量模型得到第 (3) 列模型的回归结果, 由表可知退耕还林工程依然对土壤侵蚀总量有显著的 负向影响。第 $(4) 、(5)$ 和 (6) 列反映的是使用土壤侵蚀 模数 $(S E)$ 作为被解释变量来增强模型稳健性的回归结 果,退耕还林工程对土壤侵蚀总量的负向影响依然显

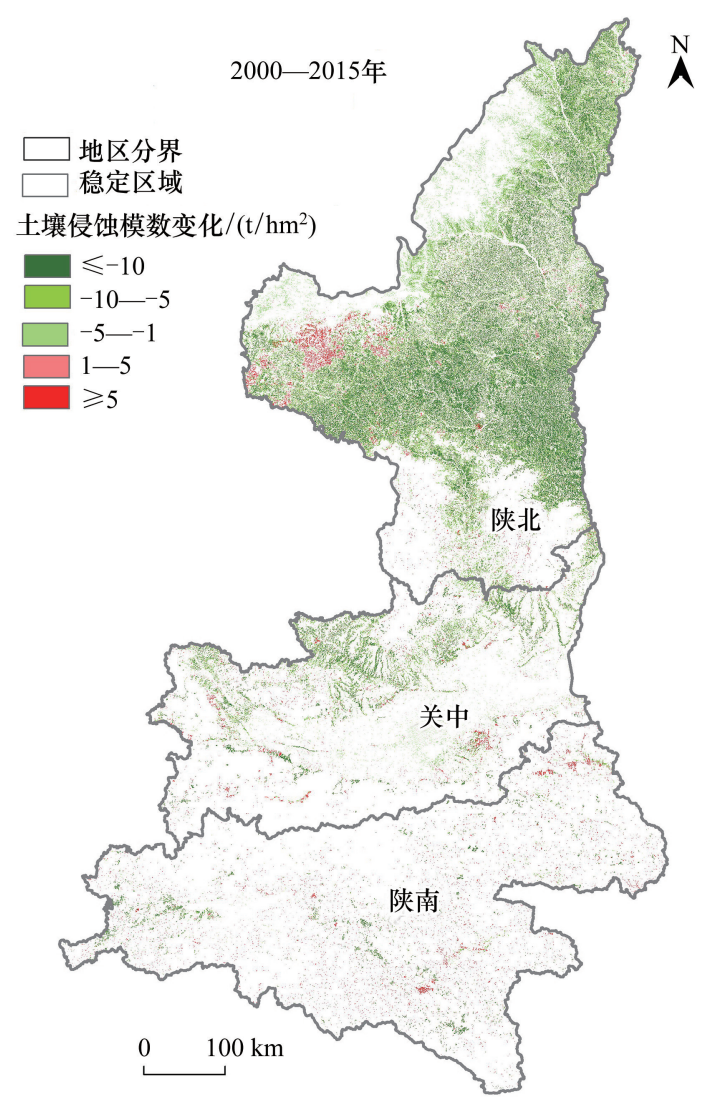

图 $32000-2015$ 年陕西省土壤侵蚀模数变化

Fig. 3 Changes of soil erosion modulus in Shaanxi Province during 2000-2015 
著。控制其他条件不变时,由表 3 中投资金额 (INV) 对应的回归系数可知,在研究期内投资金额每增加 1 亿 元, 平均土壤侵蚀模数下降 $0.7 \mathrm{t} / \mathrm{hm}^{2}$ 。考虑滞后期因素,在回归模型中加人投资金额三期滞后项 $\left(\mathrm{INV}_{-3}\right)$, 回 归结果依旧显著。

表 3 退耕还林对土壤侵蚀影响的基础回归结果

Table 3 Basic regression results of the effects of the Grain for Green Project on soil erosion

\begin{tabular}{|c|c|c|c|c|c|c|}
\hline & \multicolumn{3}{|c|}{ TSE } & \multicolumn{3}{|c|}{$S E$} \\
\hline & $(1)$ & (2) & (3) & (4) & (5) & (6) \\
\hline \multirow[t]{2}{*}{ INV } & $-0.0030^{* * *}$ & $-0.0026^{* * *}$ & & $-0.0001^{* * * *}$ & $-0.0001^{* * *}$ & \\
\hline & $(0.0002)$ & $(0.0002)$ & & $(0.0001)$ & $(0.0001)$ & \\
\hline \multirow[t]{2}{*}{$\mathrm{INV}_{-3}$} & & $-0.0020^{* * *}$ & & & $-0.0001^{* * *}$ & \\
\hline & & $(0.0002)$ & & & $(0.0001)$ & \\
\hline 控制变量 Control variable & 否 & 是 & 是 & 否 & 是 & 是 \\
\hline 县区固定效应 County-fixed effect & 是 & 是 & 是 & 是 & 是 & 是 \\
\hline 时间固定效应 Time-fixed effect & 是 & 是 & 是 & 是 & 是 & 是 \\
\hline 调整 $R^{2}$ Adjusted $R^{2}$ & 0.9762 & 0.9854 & 0.9876 & 0.9689 & 0.9830 & 0.9869 \\
\hline 样本量 Sample size & 428 & 428 & 321 & 428 & 428 & 321 \\
\hline
\end{tabular}

利用 Stata 软件计算得出,(1)括号里为稳健标准误, ***、** 和 $*$ 分别表示在 1\%,5\%和 10\% 的水平下显著;(2)本表对应回归方程见 1. 2.3 小节公式 (1); INV: 投人资金 Investment; INV-3:投人资金 3 期滞后项 Investment; TSE: 地区土壤侵蚀总量 Total soil erosion; SE: 土壤侵蚀模数 Soil erosion;

根据表 4 的回归结果可知, 人均 GDP 和农村人均收人 $(\mathrm{PRI})$ 的回归系数为负且在 $1 \%$ 置信水平上显著, 表明地区经济发展水平上升,农村人均收人的提高对防治土壤侵蚀有显著正向作用,城镇化率的回归系数为 负且在 $5 \%$ 置信水平上显著,表明随着城镇化的推进, 区域土壤侵蚀水平也会降低, 同时相关研究 ${ }^{[33]}$ 表明退耕 还林促进城镇化的加快, 进而间接影响土壤侵蚀。而工业化的回归系数为负且在 $1 \%$ 置信水平上显著, 表明 工业产业发展可能会加强区域土壤侵蚀水平,因此在工业现代化进程中要避免对生态系统产生负的外部性。 此外, 粮食产量的回归系数不显著, 但其数值为负仍然值得关注, 即虽然退耕还林工程通过将坡耕地转为林地 和草地使得土壤侵蚀降低,但由于耕地面积的减少将导致粮食产量的下降,而系数为负表明粮食产量同生态 系统服务之间可能存在协同关系,这可能与技术进步带来的粮食增产效应有关 ${ }^{[34]}$ 。

表 4 加入控制变量的退耕还林对土壤侵蚀影响的基础回归结果

Table 4 Basic regression results of the effects of the Grain for Green Project on soil erosion with control variables

\begin{tabular}{|c|c|c|c|c|c|c|c|}
\hline \multirow{2}{*}{$\begin{array}{l}\text { 解释变量 } \\
\text { Explanatory variable } \\
\text { INV }\end{array}$} & \multicolumn{7}{|c|}{$\begin{array}{c}\text { 控制变量 } \\
\text { Control variable }\end{array}$} \\
\hline & $P D$ & URBR & IS & CROP & PGDP & PRI & NDVI \\
\hline$-0.00263^{* * *}$ & -0.0046 & $-211.6170^{*}$ & $91.8586^{* * *}$ & -0.0001 & $-8.3143^{* * *}$ & $-63.4241^{* * *}$ & $-596.4611^{* * *}$ \\
\hline$(0.00017)$ & $(0.0039)$ & (115.0469) & $(24.9035)$ & $(0.0001)$ & $(1.6793)$ & $(14.9331)$ & (50.5968) \\
\hline $\begin{array}{l}\text { 县区固定效应 } \\
\text { County-fixed effect }\end{array}$ & \multicolumn{7}{|c|}{ 是 } \\
\hline $\begin{array}{l}\text { 时间固定效应 } \\
\text { Time-fixed effect }\end{array}$ & \multicolumn{7}{|c|}{ 是 } \\
\hline 调整 $R^{2}$ Adjusted $R^{2}$ & \multicolumn{7}{|c|}{0.9854} \\
\hline 样本量 Sample size & \multicolumn{7}{|c|}{428} \\
\hline
\end{tabular}

此表显示内容为表 3 中第 (3) 列加人控制变量后模型中各变量回归系数的结果; PD: 人口密度 Population density; URBR: 城镇化率 Urbanization rate; IS: 产业结构 Industrial structure; CROP : 粮食产量 CROP; PGDP : 人均国内生产总值 Per GDP; PRI: 农村人均年收人 Per rural income; NDVI: 植被归一化指数 NDVI

2.2.2 地理区位特征的影响

陕西省南北狭长, 区域自然条件以及社会经济发展的差异, 将其分为资源禀赋差异显著的三大地区, 陕 
北,关中,陕南地区 ${ }^{[35]}$, 而地理区位的不同则会使退耕还林对土壤侵蚀防治效应呈现区域异质性。表 5 回归 结果反映了不同地理区位对退耕还林工程土壤侵蚀防治效应影响的差异,同时考虑到三大地区由南向北依此 分布,加人纬度 $(\mathrm{LONG})$ 变量来检验模型结果的稳健性。

由表 5 回归结果可知,相对于关中和陕南地区,陕北地区退耕还林工程对土壤侵蚀有显著的负向影响,虽 然陕南地区系数也为负,但其系数的回归结果不显著。回归结果表明退耕还林工程的防治土壤侵蚀效应存在 显著的空间异质性,陕北地区作为黄土高原典型的生态脆弱区, 研究初期植被覆盖度较低,加之地形沟壑纵 横, 坡度起伏大, 土壤侵蚀风险较高, 而随着退耕还林工程逐步实施, 其植被覆盖水平显著提升, 同时陕北地区 降雨量相较于其他地区较小, 因此土壤侵蚀强度降低的潜力就大, 工程投资对促进其生态系统服务恢复的效 果更为显著 ${ }^{[36-37]}$,所以工程减少水土流失,防治土壤侵蚀的作用相较其他地区更为突出。而关中,陕南地区 退耕还林工程防治土壤侵蚀效应则相对较小,在统计结果上不显著,关中地区主要以平原耕地为主,工程实施 力度相对较小, 则工程对土壤侵蚀的改善作用不显著; 陕南地区位于秦巴山区腹地, 平均降雨量较大, 坡度大, 同时本身植被覆盖状况良好,工程提升其植被覆盖水平的潜力较小,降雨,坡度等自然因素对土壤侵蚀起主导 作用,故表现为退耕还林投资对土壤侵蚀的影响不显著,存在潜在的提升空间。利用纬度 (LONG) 变量替代 地区虚拟变量进行回归, 结果如第(2)列所示, 表明纬度越高的地区其退耕还林工程的土壤侵蚀防治效应更 显著, 与以上结果基本一致。同时更换被解释变量为土壤侵蚀模数 $(S E)$ 增强模型稳健性, 回归结果如第 (3), (4) 所示, 陕北地区系数仍然为负且显著, 结论与上述一致。

表 5 地理区位特征对退耕还林土壤侵蚀防治效应的影响

Table 5 The influence of geographical location characteristics on soil erosion control effect of the Grain for Green Project

\begin{tabular}{|c|c|c|c|c|}
\hline & \multicolumn{2}{|c|}{ TSE } & \multicolumn{2}{|c|}{$S E$} \\
\hline & (1) & (2) & (3) & (4) \\
\hline \multirow[t]{2}{*}{ INV $\times$ SHANBEI } & $-0.0032 * * *$ & & & $-0.0001^{* * *}$ \\
\hline & $(0.0006)$ & & & $(0.0000)$ \\
\hline \multirow[t]{2}{*}{ INV $\times$ SHANNAN } & -0.0002 & & & -0.0000 \\
\hline & $(0.0006)$ & & & $(0.0000)$ \\
\hline \multirow[t]{2}{*}{$\mathrm{INV} \times \mathrm{LONG}$} & $-0.0006^{* * *}$ & & & $-0.0000^{* * *}$ \\
\hline & $(0.0001)$ & & & $(0.0000)$ \\
\hline \multirow[t]{2}{*}{ INV } & 0.0005 & 0.0183 & 0.0000 & 0.0007 \\
\hline & $(0.0007)$ & $(0.0022)$ & $(0.0000)$ & $(0.0001)$ \\
\hline 控制变量 Control variable & 是 & 是 & 是 & 是 \\
\hline 县区固定效应 County-fixed effect & 是 & 是 & 是 & 是 \\
\hline 时间固定效应 Time-fixed effect & 是 & 是 & 是 & 是 \\
\hline 调整 $R^{2}$ Adjusted $R^{2}$ & 0.9897 & 0.9883 & 0.9872 & 0.9856 \\
\hline 样本量 Sample size & 428 & 428 & 428 & 428 \\
\hline
\end{tabular}

(1)本表对应的回归方程见 1.2 .3 小节的公式 (2),将地理区位虚拟变量与投资金额 (INV) 的交叉项带入模型;SHANBEI: 陕北地区 Shanbei; GUANZHONG : 关中地区 Guanzhong; SHANNAN : 陕南地区 Shannan; LONG : 经度 Longitude

\subsection{3 自然地理条件的影响}

自然地理条件主要通过影响土壤侵蚀的物理发生过程和地表植被覆盖, 进而对退耕还林工程的土壤侵蚀 防治效应产生调节作用, 表 6 分别列出了坡度 (SLOP), 年均降雨(PRE) 和日照时间 (SUN) 对退耕还林工程防 治土壤侵蚀效应的调节作用回归结果。

(1) 坡度对退耕还林工程防治土壤侵蚀效应存在显著的负向影响。表 6 第 (1) 列结果显示,投资金额和 坡度的交叉项回归系数为正, 且在 $1 \%$ 置信水平上显著。表明随着坡度的上升, 土壤侵蚀总量也会变大, 即退 耕还林工程减弱土壤侵蚀的效果将降低,这反映出地形坡度因素对加剧土壤侵蚀物理过程的显著作用,同时 在坡度较大地区实施退耕还林工程减缓土壤侵蚀的效应也难以突显,具体表现在由于陕南地区平均坡度相对 
较大,则根据 2.2.2 小节可知,退耕还林工程投资对陕南地区土壤侵蚀的影响不显著。在区域生态修复工程 实施过程中应充分考虑地形坡度因素, 对生态系统服务在地形地势上的空间异质性提出针对性方案, 从而提 升工程生态效益。同时更换被解释变量为土壤侵蚀模数 $(S E)$ 增强模型稳健性, 其回归结果如第 $(4)$ 列所示, 结论同上述一致。

(2) 降雨同样对退耕还林工程防治土壤侵蚀效应存在显著的负向影响。表 6 第(2)列结果显示, 投资金 额和降雨的交叉项回归系数为正, 且在 $1 \%$ 置信水平上显著。表明降雨越大, 降雨侵蚀力也会越强,则区域土 壤侵蚀总量随之变大, 即退耕还林工程减弱土壤侵蚀的效果也将降低, 这反映出降雨即降雨侵蚀力对加强土 壤侵蚀的显著作用, 使得退耕还林工程对土壤侵蚀的防治效果被部分降雨带来的土壤侵蚀抵消, 工程减弱土 壤侵蚀的效应下降。显然降雨因素在土壤侵蚀发生过程中存在复杂的调节机理 ${ }^{[5]}$, 表现在通过促进植被生 长 $^{[9]}$ 从而对土壤侵蚀有间接减弱作用以及对土壤侵蚀物理过程的直接增强作用,因此充分厘清气候条件对 生态系统服务的复合影响机理是保证区域生态修复政策可持续性的关键。同时更换被解释变量为土壤侵蚀 模数 (SE) 增强模型稳健性,其回归结果如第 (5)列所示,结论同上述一致。

(3) 与坡度和降雨的调节作用不同, 日照时间 (SUN) 对退耕还林工程防治土壤侵蚀效应存在显著的正向 影响。表 6 第(3)列结果显示, 投资金额和日照时间的交叉项回归系数为正,且在 $1 \%$ 置信水平上显著。表明 随着日照时间的增加,其对退耕还林工程减弱土壤侵蚀的效果将增强。这反映出日照时间在退耕还林工程防 治土壤侵蚀效应的正向调节作用,其生态学意义表现为日照时间更长的区域,植物光合作用越强,树叶生长越 茂密,进而增强植被减弱土壤侵蚀的效应,使得土壤侵蚀总量下降,退耕还林工程的生态效益更为显著。不同 气候条件对于生态系统服务和功能存在异质性,在实施生态修复过程中应针对区域对生态系统起主导作用的 自然地理条件进行科学分析和应对。同时更换被解释变量为土壤侵蚀模数 $(S E)$ 增强模型稳健性, 其回归结 果如第 (6)列所示, 结论同上述一致。

表 6 自然地理条件对退耕还林土壤侵蚀防治效应的影响

Table 6 The influence of natural condition on soil erosion control effect of the Grain for Green Project

\begin{tabular}{|c|c|c|c|c|c|c|}
\hline & \multicolumn{3}{|c|}{ TSE } & \multicolumn{3}{|c|}{$S E$} \\
\hline & (1) & (2) & (3) & (4) & (5) & (6) \\
\hline \multirow[t]{2}{*}{ INV $\times$ SLOP } & $0.0173^{* * * *}$ & & $0.0004^{* * *}$ & & & \\
\hline & $(0.0029)$ & & $(0.0001)$ & & & \\
\hline \multirow[t]{2}{*}{$\mathrm{INV} \times \mathrm{PRE}$} & $0.0037^{* * *}$ & & $0.0001^{* * * *}$ & & & \\
\hline & $(0.0005)$ & & $(0.0000)$ & & & \\
\hline \multirow[t]{2}{*}{$\mathrm{INV} \times \mathrm{SUN}$} & & $-0.0019^{* * * *}$ & & $-0.0001^{* * *}$ & & \\
\hline & & $(0.0003)$ & & $(0.0000)$ & & \\
\hline \multirow[t]{2}{*}{ INV } & $-0.0055^{* * *}$ & $-0.0048^{* * * *}$ & $0.0018^{* * *}$ & $-0.0002^{* * *}$ & $-0.0002^{* * *}$ & $0.0001 * * *$ \\
\hline & $(0.0005)$ & $(0.0003)$ & $(0.0008)$ & $(0.0000)$ & $(0.0000)$ & $(0.0000)$ \\
\hline $\begin{array}{l}\text { 控制变量 } \\
\text { Control variable }\end{array}$ & 是 & 是 & 是 & 是 & 是 & 是 \\
\hline $\begin{array}{l}\text { 县区固定效应 } \\
\text { County-fixed effect }\end{array}$ & 是 & 是 & 是 & 是 & 是 & 是 \\
\hline $\begin{array}{l}\text { 时间固定效应 } \\
\text { Time-fixed effect }\end{array}$ & 是 & 是 & 是 & 是 & 是 & 是 \\
\hline 调整 $R^{2}$ Adjusted $R^{2}$ & 0.9869 & 0.9879 & 0.9869 & 0.9837 & 0.9854 & 0.9845 \\
\hline 样本量 Sample size & 428 & 428 & 428 & 428 & 428 & 428 \\
\hline
\end{tabular}

\section{3 结论与讨论}

3.1 结论

本文在利用 RUSLE 模型评估陕西省 2000-2015 年土壤侵蚀水平的基础上,构建面板数据固定效应模 
型,在自然因素和社会经济因素交互作用下,探究陕西省地理特征对退耕还林工程防治土壤侵蚀的影响,主要 结论如下:

(1) 2000 年到 2015 年陕西省土壤侵蚀模数和侵蚀总量均显著降低,侵蚀总量从 2000 年到 2015 年下降 近 30\%, 区域土壤侵蚀和水土流失问题得到有效缓解。其中,陕北地区土壤侵蚀面积占比最大,强度最高, 同 时较关中和陕南地区, 其土壤侵蚀强度下降也最为明显,这得益于退耕还林工程持续性和全面性的资金投人。

(2)退耕还林工程对防治土壤侵蚀存在显著的正向影响,投入资金越高则减弱土壤侵蚀效应越强,投资 金额每增加 1 万元, 土壤侵蚀总量降低 $26.30 \mathrm{t}$, 且资金投人的生态效应存在显著的 3 期滞后。同时这种影响 呈现显著空间异质性,即地理区位的调节作用显著,表现为陕北地区退耕还林工程对土壤侵蚀的影响最为显 著, 陕南和关中地区的回归系数则不显著。而自然地理特征中, 降雨和坡度对退耕还林工程防治土壤侵蚀效 应存在显著的负向调节作用, 即随着降雨或坡度的增加, 工程防治土壤侵蚀的效应将降低, 而日照时间则存在 显著的正向调节作用,即在日照时间更长的区域,退耕还林工程防治土壤侵蚀的效应更强。

\section{2 讨论}

退耕还林工程防治土壤侵蚀以及提升生态系统服务功能的显著作用已被学术界广泛研究和证实 ${ }^{[38-39]}$, 同时大量社会经济学者也关注退耕还林工程对粮食生产 ${ }^{[34]}$,农民收人结构 ${ }^{[40]}$, 劳动力转移 ${ }^{[41]}$ 的影响。土壤 侵蚀作为自然和人为因素交互的结果,应该将社会经济因素纳人分析退耕还林工程对土壤侵蚀影响机制的框 架之中, 否则会造成政策评估的偏差。同时地理特征的异质性对于土壤侵蚀的影响极为显著, 特别是在较小 尺度土壤侵蚀研究中,坡度,降雨等自然地理条件在土壤侵蚀过程中更是起到主导作用。本研究在计量模型 中通过构建地理特征与退耕还林工程投资金额的交互项,将政策因素同自然因素结合起来纳人生态修复工程 的效果评价体系中,有利于政策评估的系统性和政策实施的可持续性。同时使用资金投人来表征政策实施的 强度, 相较直接使用土地利用类型间转换数量有更强的代表性，也有助于衡量资金投人的有效性。计量回归 结果还可得出区域投入资金与生态效益之间存在的定量关系,而不同地理区位存在着显著差异,则该定量关 系和差异就可作为制定政策资金投人和补贴标准的依据，同时可借助大数据平台,将退耕还林地块“上图人 库”为后期管理和维护提供科学支撑, 以便针对其社会经济特征以及自然地理条件精准施策。同时,在制定 和实施生态修复政策时应注重同区域社会经济发展的协调耦合, 就陕北, 陕南和关中地区而言, 分别承载着不 同的区域功能。陕南是重要的生态功能区, 应继续作为生态保护的重点, 出台落实相应的保护法规, 保障退耕 成果; 关中是人口集聚区和农业主产区, 应注重人地关系的协调发展, 可发展林下经济, 调整生态林和经济林 的比例; 陕北是典型的生态脆弱区, 则应通过延长补助期限, 增加补助金额等措施推进生态修复工程, 巩固生 态成果。同时,在此基础上还应进一步厘清自然地理条件对生态系统服务的复合影响机理,有针对性的提高 和改善区域生态系统服务和功能。

以退耕还林工程为代表的生态修复工程在提升区域生态系统服务和功能的同时,对区域社会经济发展也 会带来影响, 而这些社会经济因素的改变也必然会反作用于生态系统。比如城镇化进程的加快, 对水资源, 空 气质量带来负的外部性压力, 同时在自然因素与社会经济要素的交互作用下, 如何制定更为全面和系统的生 态政策来应对生态系统服务和社会经济发展之间存在的权衡和协同关系将是决策者和学术界关注的重点。 此外本研究在以下两方面还需进一步完善和改进: (1) 如何在社会经济因素和自然因素的交互作用和多种生 态系统服务存在权衡和协同关系时,科学评估生态修复工程投人资金的效率以实现政策实施的可持续性。 (2) 由于数据获取原因, 利用 RUSLE 模型评估土壤侵蚀水平时多借鉴前人研究参数, 对精准评估区域土壤侵 蚀水平可能存在一定误差, 寻找更为适合样本的参数本地化方法是下一步努力的方向。

\section{参考文献 (References) :}

[ 1 ] Amundson R, Berhe A A, Hopmans J W, Olson C, Sztein A E, Sparks D L. Soil and human security in the 21st century. Science, 2015, 348 (6235): 1261071.

[ 2 ] Borrelli P, Robinson D A, Fleischer L R, Lugato E, Ballabio C, Alewell C, Meusburger K, Modugno S, Schütt B, Ferro V, Bagarello V, van 
Oost K, Montanarella L, Panagos P. An assessment of the global impact of 21st century land use change on soil erosion. Nature Communications, $2017,8: 2013$.

[3] 李智广, 曹炜, 刘秉正, 罗志东. 我国水土流失状况与发展趋势研究. 中国水土保持科学, 2008, 6(1): 57-62.

[4] 王占礼. 中国土壤侵蚀影响因素及其危害分析. 农业工程学报, 2000，16(4): 32-36.

[ 5 ] 陈浩. 黄土高原退耕还林前后流域土壤侵蚀时空变化及驱动因素研究 [D]. 杨凌: 西北农林科技大学, 2019.

[ 6 ] Kong L Q, Zheng H, Rao E M, Xiao Y, Ouyang Z Y, Li C. Evaluating indirect and direct effects of eco-restoration policy on soil conservation service in Yangtze River Basin. Science of the Total Environment, 2018, 631-632: 887-894.

[ 7 ] 赖亚飞, 朱清科, 李文华. 生态环境建设工程的效益评价研究与进展. 西北林学院学报, 2007, 22(1): 168-172.

[ 8 ] Liu F, Yan H M, Gu F X, Niu Z E, Huang M. Net primary productivity increased on the Loess Plateau following implementation of the Grain to Green Program. Journal of Resources and Ecology, 2017, 8(4): 413-421.

[9] 吴秀芹, 蔡运龙. 土地利用/土地覆盖变化与土壤侵蚀关系研究进展. 地理科学进展, 2003, 22(6): 576-584.

[10］李天宏, 郑丽娜. 基于 RUSLE 模型的延河流域 2001-2010 年土壤侵蚀动态变化. 自然资源学报, 2012, 27(7)：1164-1175.

[11] 许月卿, 邵晓梅. 基于 GIS 和 RUSLE 的土壤侵蚀量计算一一贵州省猫跳河流域为例. 北京林业大学学报, 2006, 28(4): 67-71.

[12] 郭思琪, 韩磊, 赵永华, 员学锋, 王达, 李蕴琪. 秦岭地区土壤侵蚀时空变化及景观格局. 生态学杂志, 2019, 38(7) : 2167-2176.

[13] 王欢, 高江波, 侯文娟. 基于地理探测器的喀斯特不同地貌形态类型区土壤侵蚀定量归因. 地理学报, 2018, 73(9)：1674-1686.

[14] 陈思旭, 杨小唤, 肖林林, 蔡红艳. 基于 RUSLE 模型的南方丘陵山区土壤侵蚀研究. 资源科学, 2014, 36(6)：1288-1297.

[15] 王涛. 基于 RUSLE 模型的土壤侵蚀影响因素定量评估: 以陕北洛河流域为例. 环境科学与技术, 2018, 41(8)：170-177.

[16] 刘文超, 刘纪远, 匡文慧. 陕北地区退耕还林还草工程土壤保护效应的时空特征. 地理学报, 2019, 74(9)：1835-1852.

[17] 牛丽楠, 邵全琴, 刘国波, 唐玉芝. 六盘水市土壤侵蚀时空特征及影响因素分析. 地球信息科学学报, 2019, 21 (11): $1755-1767$.

[18] Rao E M, Xiao Y, Ouyang Z Y, Zheng H. Changes in ecosystem service of soil conservation between 2000 and 2010 and its driving factors in Southwestern China. Chinese Geographical Science, 2016, 26(2) : 165-173.

[19] Yin R S, Zhao M J. Ecological restoration programs and payments for ecosystem services as integrated biophysical and socioeconomic processesChina's experience as an example. Ecological Economics, 2012, 73: 56-65.

[20］张义学, 张静. 黄色到黛绿的嬗变——陕西“退耕还林” 20 年发展扫描. 西部大开发, 2018(12): 94-97.

[21] 黄富祥, 康慕谊, 张新时. 退耕还林还草过程中的经济补偿问题探讨. 生态学报, 2002, 22(4): 471-478.

[22] 陈强. 高级计量经济学及 Stata 应用(第二版). 北京: 高等教育出版社, 2014.

[23] 胡艺, 张晓卫, 李静. 出口贸易、地理特征与空气污染. 中国工业经济, 2019, (9) : 98-116.

[24] 章文波, 付金生. 不同类型雨量资料估算降雨侵蚀力. 资源科学, 2003, 25(1)：35-41.

[25] 蔡崇法, 丁树文, 史志华, 黄丽, 张光远. 应用 USLE 模型与地理信息系统 IDRISI 预测小流域土壤侵蚀量的研究. 水土保持学报, 2000, 14(2): 19-24

[26] 符素华, 刘宝元, 周贵云, 孙中轩, 朱小立. 坡长坡度因子计算工具. 中国水土保持科学, 2015, 13(5): 105-110.

[27］王超. 基于 RS/GIS 的渭河流域土壤侵蚀评价研究 [D]. 西安: 西北大学, 2010 .

[28] 刘纪远, 宁佳, 匡文慧, 徐新良, 张树文, 颜长珍, 李仁东, 吴世新, 胡云锋, 杜国明, 迟文峰, 潘涛, 宁静. 2010-2015 年中国土地利用 变化的时空格局与新特征. 地理学报, 2018, 73(5): 789-802.

[29］陕西省统计局, 国家统计局陕西调查总队. 陕西统计年鉴. 北京: 中国统计出版社, 2001-2016.

[30］中华人民共和国水利部. SL 190-2007 土壤侵蚀分类分级标准. 北京: 中国水利水电出版社, 2008.

[31] Yin R S, Yin G P. China's primary programs of terrestrial ecosystem restoration: initiation, implementation, and challenges. Environmental Management, 2010, 45(3): 429-441.

[32] 王怡菲, 姚顺波, 邓元杰. 渭河流域水土流失治理效率的时空格局演化与影响因素. 地理科学, 2019, 39(5): 836-846.

[33] Li T, Lü Y H, Fu B J, Comber A J, Harris P, Wu L H. Gauging policy-driven large-scale vegetation restoration programmes under a changing environment: their effectiveness and socio-economic relationships. Science of the Total Environment, 2017, 607-608: 911-919.

[34] 国家统计局课题调研组. 退耕还林对西部地区粮食生产及供求的影响. 管理世界, 2004, (11): 97-100, 108-108.

[35] 安树伟, 王海波, 张建肖. 主体功能区建设研究——基于陕西省三大区域协调发展的考察. 学习与实践, 2008, (3): 37-43.

[36] 侯孟阳，姚顺波，邓元杰，丁振民，鲁亚楠，郑雪，李雅男. 格网尺度下延安市生态服务价值时空演变格局与分异特征一基于退耕还 林工程的实施背景. 自然资源学报, 2019, 34(3) : 539-552.

[37] 谢怡凡, 姚顺波, 邓元杰, 贾否, 李园园, 高晴. 延安市退耕还林(草)工程对生境质量时空格局的影响. 中国生态农业学报(中英文), $2020,28(4): 575-586$.

[38] Jiang W G, Yuan L H, Wang W J, Cao R, Zhang Y F, Shen W M. Spatio-temporal analysis of vegetation variation in the Yellow River Basin. Ecological Indicators, 2015, 51: 117-126.

[39] Lü Y H, Fu B J, Feng X M, Zeng Y, Liu Y, Chang R Y, Sun G, Wu B F. A policy-driven large scale ecological restoration: Quantifying ecosystem services changes in the Loess Plateau of China. PLoS One, 2012, 7(2): e31782.

[40] 徐晋涛, 陶然, 徐志刚. 退耕还林: 成本有效性、结构调整效应与经济可持续性一一基于西部三省农户调查的实证分析. 经济学 (季刊), 2004, (4) : 139-162.

[41] 刘越, 姚顺波. 不同类型国家林业重点工程实施对劳动力利用与转移的影响. 资源科学, 2016, 38(1)：126-135. 